Res., Soc. Dev. 2019; 8(5):e2685978

ISSN 2525-3409 | DOI: http://dx.doi.org/10.33448/rsd-v8i5.978

\title{
A paisagem do perímetro urbano do rio Grajaú (Maranhão) analisada a partir de indicadores de qualidade visual
}

The landscape of the urban perimeter of the Grajaú river (Maranhão) analyzed from visual quality indicators
El paisaje del perímetro urbano del río Grajaú (Maranhão) analizada a partir de indicadores de calidad visual

Carlos Antonio de Souza Lima ORCID: https://orcid.org/0000-0001-9462-0793

Universidade Federal do Maranhão/Câmpus de Grajaú, Brasil E-mail: carlosousa93@hotmail.com

Marcos Nicolau Santos da Silva ORCID: https://orcid.org/0000-0003-0311-4559 Universidade Federal do Maranhão/Câmpus de Grajaú, Brasil E-mail: marcos.nicolau@yahoo.com.br

Recebido: 16/02/2019 | Revisado: 27/02/2019 | Aceito: 02/03/2019 | Publicado: 06/03/2019

\section{Resumo}

Este trabalho aborda a percepção ambiental e a análise da paisagem do perímetro urbano do Rio Grajaú, na cidade de mesmo nome, estado do Maranhão. O objetivo foi analisar a percepção ambiental da população grajauense em relação às mudanças ocorridas na paisagem do rio Grajaú, bem como os impactos gerados pelas atividades humanas ao longo dos últimos anos. A pesquisa foi qualitativa e a metodologia constituiu-se de revisão bibliográfica acerca dos termos paisagem e percepção ambiental nas abordagens geográficas e utilizaram-se os indicadores da qualidade visual da paisagem, proposta metodológica adaptada de Pires (2005). Para se verificar o grau de percepção ambiental da população, foram realizadas entrevistas semiestruturadas. Os resultados mostraram que a paisagem do rio Grajaú apresenta média qualidade visual e, embora a população apresente sensibilidade em relação à situação do rio, são poucas as ações para a sua conservação.

Palavras-chave: Paisagem; Percepção Ambiental; Rio Grajaú; Indicadores de Qualidade Visual. 


\section{Abstract}

This paper analyzes the environmental perception and the analysis of the landscape of the urban perimeter of the Grajaú river, in the city of the same name, state of Maranhão - Brazil. The objective was to analyze the environmental perception of grajauense population in relation to changes in the landscape of Grajaú river, as well as the impacts generated by human activities over the past few years. The research was qualitative and the methodology consisted of bibliographical review about the landscape and environmental perception terms in geographical approaches and were used in the indicators visual quality of the landscape, methodological approach adopted from Pires (2005). To check the degree of environmental perception of population were conducted semi-structured interviews. The results showed that the landscape of the Grajaú river presents average visual quality and although the population has sensitivity in relation to the situation of the river, there is little actions for their conservation.

Keywords: Landscape; Environmental Perception; Grajaú River; Visual Quality Indicators.

\section{Resumen}

Este trabajo aborda la percepción ambiental y el análisis del paisaje del perímetro urbano del río Grajaú, en la ciudad del mismo nombre, Maranhão - Brasil. El objetivo fue analizar la percepción ambiental de la población grajauense en relación a los cambios ocurridos en el paisaje del río Grajaú, así como los impactos generados por las actividades humanas a lo largo de los últimos años. La investigación fue cualitativa y la metodología se constituyó de revisión bibliográfica acerca de los términos paisaje y percepción ambiental en los abordajes geográficos y se utilizaron los indicadores de la calidad visual del paisaje, propuesta metodológica adaptada de Pires (2005). Para verificar el grado de percepción ambiental de la población, se realizaron entrevistas semiestructuradas. Los resultados mostraron que el paisaje del Río Grajaú presenta media calidad visual y, aunque la población presenta sensibilidad respecto a la situación del río, son pocas las acciones para su conservación.

Palabras clave: Paisaje; Percepción Medioambiental; Río Grajaú; Indicadores de Calidad Visual.

\section{Introdução}

A recorrência sobre a importância do rio Grajaú para a cidade de mesmo nome, localizada no Centro-Sul do Maranhão, tornou-se frequente na fala dos moradores locais, pois 
foi em suas margens que a urbe surgiu e começou a se expandir. Sabe-se, através da literatura histórica e dos relatos de moradores mais antigos, que o rio possuía trechos navegáveis, utilizado para transporte de pessoas e alimentos para a cidade e região. Posteriormente, a vazão e profundidade do rio se reduziram, inviabilizando a sua navegabilidade. Entre outros fatores, a urbanização tem provocado diversos impactos sobre o sistema ambiental do rio, sobretudo no trecho urbano de Grajaú.

Tornou-se bastante frequente a queixa entre a população sobre as mudanças físicas e perceptíveis que vêm ocorrendo na paisagem do rio nos últimos anos. Observa-se, no trecho urbano, o estabelecimento de atividades econômicas que têm pressionado o espaço do rio, a exemplo de atividades de lazer, extração de areia, frigorífico, além dos problemas quanto ao lixo e esgoto urbanos. Com isso é importante saber como os moradores locais veem as modificações no rio ao longo do tempo.

Diante disso, a inquietação para o desenvolvimento da pesquisa surgiu a partir das observações prévias realizadas no entorno do rio, no perímetro urbano de Grajaú, junto à equipe interdisciplinar do PET/Ciências Naturais (Programa de Educação Tutorial) da Universidade Federal do Maranhão, Câmpus de Grajaú. As transformações e os impactos ambientais visíveis na paisagem do rio Grajaú despertaram para a necessidade de se analisálos à luz da percepção dos moradores locais.

Este trabalho visou identificar os principais problemas e impactos ambientais encontrados na paisagem do rio, de modo a fornecerem subsídios qualitativos que comprovem ou refutem a ideia de que a ação desenfreada da urbanização em torno do rio, bem como a utilização de suas margens para pontos de banho e comércio em épocas de estiagem, têm acentuado os impactos ambientais. Procurou-se verificar também se há falta de sensibilização e conscientização por parte da população, o que acabaria por agravar a situação em que o rio se encontra.

O objetivo deste artigo foi analisar a percepção ambiental da população grajauense em relação às mudanças ocorridas na paisagem do rio Grajaú, bem como os possíveis impactos gerados pelas atividades humanas sobre o ecossistema, no perímetro urbano. Assim, visou-se, ainda, entender a paisagem do rio Grajaú a partir do ponto de vista dos próprios moradores da cidade.

Como são poucos os estudos realizados, dentro ou fora da Geografia, que se tem conhecimento a respeito do rio Grajaú e da própria cidade, este trabalho se torna de fundamental importância para a comunidade em geral.

De outro lado, este trabalho objetivou identificar os impactos ambientais sobre o rio, 
presentes no perímetro urbano e buscou analisá-los à luz dos indicadores de qualidade visual, propostos por Pires (2005), a saber: diversidade, naturalidade, singularidade e detratores . O uso de tais indicadores ocorreu em pontos do rio onde há/houve maior movimentação de pessoas, como balneários, e também nas margens do rio Grajaú.

O trabalho se dividiu em três partes, sendo duas tratando do referencial bibliográfico da pesquisa e da metodologia aplicada durante o trabalho de campo, expondo os conceitos de paisagem e percepção ambiental, assim como os indicadores de qualidade visual junto de sua análise. Por último, se apresentam os resultados das entrevistas e as considerações finais da pesquisa.

\section{Paisagem e percepção ambiental: perspectivas geográficas}

Paisagem e percepção são dois conceitos com variadas definições, mas que vem sendo utilizados como uma nova maneira de pesquisar. Esta seção se dividiu em dois tópicos, referente à parte teórica da pesquisa. O primeiro tópico abordou o surgimento do conceito de paisagem, bem como de sua inserção e trajetória nas correntes geográficas. O segundo tópico abordou o conceito de percepção na Geografia, baseando-se nos escritos de alguns geógrafos.

\subsection{Paisagem nas abordagens geográficas}

Segundo Schier (2003), paisagem na sua materialidade pode ser estudada desde a formação do nosso planeta, mas é no século XV, durante o Renascimento, que se têm as primeiras formulações sobre o seu conceito. Primeiramente, seu conceito está relacionado às artes e só depois, com o fim da Idade Média, passa a ser de interesse das abordagens científicas.

Nas abordagens geográficas, os estudos dentre os quais se trabalham o conceito de paisagem passam por diversos períodos. Durante o século XIX e início do século XX, período em que a Geografia se consolidava como ciência, surge a Geografia de cunho positivista, este período é apontado como o momento das concepções geográficas tradicionais.

O conceito de paisagem é um dos mais antigos estudados na Geografia. As expedições e experiências naturalistas fundaram o seu uso na Geografia. Tal conceito na Geografia vem sendo discutido para se entender as relações sociais e naturais em um determinado espaço, mas sua interpretação é muito divergente, pois há várias correntes de pensamento, bem como a presença de diferentes concepções de paisagem. Na Geografia, os primeiros estudos que se 
utilizaram do conceito de paisagem são as obras "Cosmos" de Alexander von Humboldt, a "Geografia Comparada" de Carl Ritter e a "Antropogeografia" de Friedrich Ratzel, entre outros autores da Geografia Clássica (Schier, 2003).

O geógrafo alemão Alexander von Humboldt é considerado o pioneiro nos estudos de paisagem do século XIX. Ele considerava a Geografia como uma ciência da síntese da paisagem, que deveria ser descrita e representada. Humboldt estudava a paisagem em relação à vegetação. Com isso, a paisagem era utilizada como forma de diferenciar áreas segundo suas características morfológicas, topográficas e geológicas etc.. Nesta época, o homem não era tido como importante na paisagem, mas apenas como um mero ajudante em meio à natureza.

$\mathrm{Na}$ publicação de “Antropogeografia”, do alemão Friedrich Ratzel, paisagem é substituída por território e o homem é tido como influenciado pela natureza, ao contrário dos estudos de Humboldt. Segundo Salvio (2008, p. 7), "Ratzel definiu o objeto da Geografia como sendo o estudo da influência que as condições naturais exerciam sobre o homem", acentuando a influência do determinismo na ciência geográfica. Ratzel acreditava que a paisagem seria o resultado do distanciamento do espírito humano de seu meio natural.

Na França, surge em contraposição a Ratzel, o possibilismo, presente na obra do geógrafo Paul Vidal de La Blache. Para ele, a relação entre homem e paisagem era funcionalista, assim, ele admitia que a natureza pudesse influenciar o homem, no entanto era a maneira como o homem dominava a natureza através das técnicas que lhe possibilitava sobreviver. Assim, segundo Salvio $(2008$, p. 8), para Vidal, "o que interessaria à análise seria o resultado da ação humana na paisagem”.

Os autores citados até aqui usaram a paisagem apenas de forma fisionômica, abarcando as formas e características morfológicas de uma determinada área, servindo como forma de diferenciação de áreas, assim como relacionando-a com o gênero de vida das pessoas, que possibilitava ao homem dominar o ambiente (natureza).

Outra fase compreende a época em que emergem concepções geográficas opostas ou que criticariam as tradicionais, este período se situa no século $\mathrm{XX}$, conhecida como corrente neopositivista ou "Nova Geografia". Nesta corrente, a paisagem passou a ser interpretada a partir de modelos matemáticos e computacionais. Apesar do uso de novos métodos e técnicas para o estudo geográfico, a Nova Geografia foi definida como neopositivista, uma vez que sua proposta não eliminou a influência dos postulados positivistas. Esta abordagem considera a paisagem como o resultado da "integração entre os aspectos físicos da paisagem e o uso que o 
homem faz deste espaço" (Salvio, 2008, p. 9). Embora esta seja considerada neopositivista, por vezes, apresenta traços marcados pelo determinismo ou pelo possibilismo.

Também no mesmo período emergem concepções menos objetivas na Geografia. A corrente da Geografia da Percepção, embora minoritária, traz para os estudos geográficos um olhar subjetivo. Assim, a paisagem, enquanto conceito, ganha relevo nesta corrente e outros elementos passam a ser considerados para estudo. A paisagem, neste sentido, continua a ser o objeto de análise da observação geográfica, entretanto sua análise também pode ser feita a partir das diferentes formas de o homem sentir e perceber uma determinada porção do espaço.

Na concepção de Tuan (2012) e Maciel (2001), a paisagem abrangeria tanto a percepção como a experiência dos sujeitos no meio em que vivenciam. A Geografia da Percepção procura compreender como se dá o processo de apropriação do espaço vivenciado pelos homens, como é a consciência destes em relação ao meio que os cerca e como percebem os elementos da natureza.

Para as demais correntes paradigmáticas da Geografia, a principal crítica direcionada à Geografia da Percepção e do Comportamento é o excesso de subjetividade para se analisarem os fenômenos geográficos sobre a paisagem e o espaço. No entanto, os precursores dessa corrente defendem que as sociedades não transformam a natureza exclusivamente motivadas por razões econômicas. A organização do território traduz os valores da sociedade, as suas crenças, seus costumes e constrói laços afetivos (Salgueiro, 2001).

O mesmo autor argumenta que "quem estuda tem ideias e valores que condicionam aquilo que vê, a seleção dos elementos que vai analisar" (Salgueiro, 2001, p. 50). Concorda-se com o autor que dificilmente poderá tratar a paisagem apenas como uma realidade material objetiva.

Muller Filho (1988), citado por Cavalcanti (2011), salienta para o fato de que a paisagem em si é a melhor fonte pra se obter informações, pois nela está expressa a realidade disponível à interpretação do observador.

Outro autor que trata do estudo e definição de paisagem é o geógrafo norte-americano Carl Sauer, que se destaca dentro da Geografia Cultural clássica. Sauer (1998) coloca que a relação entre os elementos naturais e antrópicos é essencial para se entender a paisagem. Este autor cita que, para se formar a ideia de paisagem, tem que se pensar em suas relações associadas ao tempo, bem como vinculadas ao espaço. As ideias de Sauer pressupõem a distinção entre paisagem natural e cultural, mas o termo paisagem serve como um conceito unitário da Geografia para abranger as características naturais com os aspectos humanos da paisagem (Schier, 2003). 
A abordagem marxista/crítica surgiu na década de 1980 em resposta à Nova Geografia. Porém, sua crítica não se dá apenas a esta corrente teórica precedente, mas a todas às correntes já estabelecidas. Para os teóricos desta abordagem geográfica, o espaço junto à maneira como ele é constituído ou se constitui é o conceito-chave da Geografia. Neste sentido, o espaço representa o ambiente em que o homem se estabelece e funda suas atividades, e só existe se desempenhar funções sociais que tenham sentido dentro do sistema político-econômico em que se vive. Assim, a paisagem não seria objeto da Geografia, pois já não cumpre uma função social (Salvio, 2008).

Segundo Schier (2003), hoje a ideia de paisagem merece maior destaque pela avaliação ambiental e estética, pois depende da cultura das pessoas que a percebem e constroem. Este autor a denomina como sendo um produto cultural, resultando da ação das atividades humanas sobre o meio ambiente. Schier (2003, p. 80) descreve a relação entre as atividades humanas e a determinação das paisagens:

O aspecto cultural tem desempenhado um papel importante na determinação do comportamento das pessoas em relação ao ambiente. Determinadas paisagens apresentam, na sua configuração, marcas culturais e recebem, assim, uma identidade típica. A problemática ambiental moderna está ligada à questão cultural e leva em consideração a ação diferenciada do homem na paisagem. Desta forma, a transformação da paisagem pelo homem representa um dos elementos principais na sua formação.

Dentro da diversidade de conceitos referentes à paisagem, o geógrafo francês Georges Bertrand (2004, p. 141), procurando abarcá-la, trata a paisagem como um ser único que engloba de maneira homogênea a esfera natural e a cultural. Em seu texto ele coloca:

A paisagem não é a simples adição de elementos geográficos disparatados. É, em uma determinada porção do espaço, o resultado da combinação dinâmica, portanto instável, de elementos físicos, biológicos e antrópicos que, reagindo dialeticamente uns sobre os outros, fazem da paisagem um conjunto único e indissociável, em perpétua evolução.

Ao final de seu texto, Schier (2002) coloca que hoje é possível perceber a existência conceitual de várias paisagens, deixando um grande desafio para a Geografia como um todo. Assim sendo, percebe-se que o conceito de paisagem, entre os geógrafos, sejam eles físicos ou humanistas/culturalistas, segue uma proposta de estudo mais centrada em concepções integradas e/ou inter-relacionais. Todavia, os estudos recentes apontam ainda para a necessidade de agregar e expandir a análise e interpretação da paisagem de modo interdisciplinar, como indicam os trabalhos de Schier (2002), Moura \& Simões (2010). 


\subsection{Notas sobre a percepção ambiental}

Em uma consulta ao dicionário, encontram-se várias denominações para o termo/verbo percepção/perceber. Percepção, de forma genérica, é entendida como o ato de perceber. A designação mais próxima do sentido deste trabalho para o verbo perceber é: captar através dos sentidos; entender, compreender (Santiago-Almeida, 2011).

Comumente, no meio social ou até mesmo no meio acadêmico, o termo percepção é confundido com a observação. Na Geografia, a observação é um dos métodos mais antigos utilizados para analisar a paisagem e estudos de laboratório. Não raro, os geógrafos também cometem equívocos ao utilizar palavras como "olhar", "observar" e "perceber".

De acordo com Cavalcanti (2011, p. 119), “na observação, não é só o sentido da visão que é utilizado, mas também a consciência (a razão, o raciocínio)”. A observação, nesse sentido, depende da capacidade de síntese, análise e domínio de noções e conceitos prévios do observador, pois é extremamente difícil observar a totalidade de modo integrado. Isso está relacionado ao fato de o pesquisador/observador selecionar os elementos que se pretende estudar, além de que a observação tem a ver com a visão de mundo, os conceitos, os valores e a área de formação do sujeito. Neste caso, tem-se a passagem do procedimento de observar para perceber o objeto.

Lívia de Oliveira considera que há outras noções importantes quando associadas ao conceito de percepção ambiental: sensação, percepção, atividade perceptiva, cognição e representação. Segundo a autora, o início da experiência humana ou contato do pesquisador em relação ao meio ambiente se dá a partir das sensações, através dos órgãos sensoriais: visão, audição, olfato, paladar e tato. Já a percepção ocorre no córtex cerebral, que, em um determinado momento, corresponde à sensação. Dessa forma, cada sujeito percebe a paisagem e o espaço de forma diferenciada porque a sensação é individualizada (Oliveira, 2012).

Nesse caminho, entre a percepção e a cognição há uma etapa importante que é a atividade perceptiva. Nesta fase destaca-se a inteligência como um sistema de ações e operações agrupadas. Eis aí o que se denomina de função intelectual, em seu aspecto dinâmico. A percepção e a inteligência constituem a cognição (Oliveira, 2012).

O estudo de percepção ambiental não é diferente do de paisagem, pois há várias maneiras de se pensar o que é percepção ambiental. Neste cenário se destaca o geógrafo chinês Yi-Fu Tuan, que constrói o conceito que intitula o seu livro Topofilia (2012), abarcando todos os laços afetivos entre os seres humanos e o meio ambiente. 
Percepção é o ato de perceber, distinguir. A percepção é diferente para cada indivíduo, pois cada um tem sua maneira de ver o mundo. No Brasil há dois principais autores que se destacam na abordagem da percepção ambiental: Lívia de Oliveira e Oswaldo Bueno de Amorim Filho.

De acordo com Amorim Filho (2002), a atividade geográfica sempre se baseou nas percepções ambientais de seus praticantes, porém, nas décadas de 1960-1970, se observa um verdadeiro resgate e uma nova valorização nessa maneira de exploração de lugares e paisagens da Terra. Isto se dá pelo fato de as correntes dominantes na época relegarem um plano secundário ao contato com a realidade concreta e com as representações que os homens fazem dela. Assim, os estudos de percepção ambiental foram incluídos em um grande movimento denominado, na década de 1970, de "Geografia Humanista".

Segundo Oliveira (2012, p. 59-60):

\begin{abstract}
Alguns autores preferem a denominação percepção do meio ambiente, ao termo percepção ambiental, pois o primeiro é mais abrangente, mais compreensivo, quando adjetivamos a percepção restringimos o seu significado. Contudo, o que parece é que a maioria dos estudiosos vem trabalhando mais com percepção ambiental, do que propriamente com a percepção do meio ambiente.
\end{abstract}

Nos últimos anos foram abertas novas perspectivas para profissionais e estudiosos interessados em meio ambiente, abarcando desde planejadores, arquitetos, geógrafos, urbanistas, economistas, sociólogos, psicólogos, ecólogos, juristas, biólogos até educadores. Com isso, segundo Oliveira (2012), não é fácil definir este conceito, pois cada profissional atribui significados diferentes à percepção ambiental, podendo estar relacionada aos aspectos culturais, econômicos, artísticos, geográficos, históricos, afetivos e ecológicos.

A referida autora explica ainda que:

Quando se trata de percepção ambiental, trata-se, no fundo, de visão de mundo, de visão de meio ambiente físico, natural e humanizado, na maioria é sociocultural e parcialmente é individual; é experiência em grupo ou particularizada; é uma atitude, uma posição, um valor, uma avaliação que se faz do nosso ambiente (Oliveira, 2012, p. 61).

Lembrando que, de acordo com Tuan (2012), a visão de mundo se refere à experiência conceitualizada. Logo, reconhece-se que, apesar de cada pessoa ser um organismo biológico, um ser social e um indivíduo único, conforme frisa o autor, tanto a experiência individual quanto a coletiva, sendo objeto ou sujeito da pesquisa, vai produzir a percepção a partir das vivências e dos conceitos internalizados e externalizados. 
Paisagem e percepção andam lado a lado, pois a paisagem só é obtida através dos sentidos, tendo como principal a visão, e a percepção é construída através de nossos sentidos e sentimentos/sensações. Ambas podem ser trabalhadas juntas.

A pesquisa desenvolvida baseou-se na percepção ambiental, ou seja, na visão de mundo dos moradores locais a respeito da paisagem em torno do rio Grajaú, sendo que estas podem estar embasadas em aspectos culturais, econômicos, políticos, entre outros. Além disso, a percepção ambiental neste trabalho é complementada pela visão de mundo do investigador, análise e interpretação dos indicadores de qualidade visual da paisagem.

\section{Indicadores de qualidade visual: uma proposta metodológica}

Este tópico discorre a respeito dos indicadores de qualidade visual, proposta metodológica adotada por Pires (2005), para a análise da qualidade visual das paisagens. Enquanto Pires (2005) caracterizou as paisagens turísticas do distrito-sede de Porto Belo/SC através dos indicadores, esta pesquisa se propôs a analisar principalmente o nível de detração das paisagens do rio Grajaú.

Para a caracterização das paisagens estudadas, foram escolhidos alguns pontos do rio ao longo do perímetro urbano de Grajaú e realizados os registros fotográficos, para análise dos indicadores de qualidade visual, levando-se em conta os parâmetros estabelecidos por cada um dos indicadores. A seleção das imagens foi realizada de acordo com os elementos que compõem a paisagem, considerando a naturalidade e os elementos detratores.

Os indicadores foram divididos por Pires (2005) em quatro grupos: diversidade, naturalidade, singularidade e detratores. Cada indicador apresenta um conjunto de características que permitirão sua análise.

Para a coleta dos dados, foram adaptados os quadros desenvolvidos por Pires (2005). No início foi construída a identificação, estruturada em um cabeçalho, contendo os campos para informações de controle, conforme se mostra a seguir no Quadro 1:

Quadro 1 - Dados de identificação

\begin{tabular}{|c|c|c|}
\hline \multicolumn{3}{|c|}{ Responsável: __ _ Local/Data: } \\
\hline Ponto de observação: & Cena observada: & Foto $\mathrm{n}^{\circ}$ : \\
\hline
\end{tabular}

Fonte: Adaptado de Pires (2005). 


\section{Res., Soc. Dev. 2019; 8(5):e2685978}

ISSN 2525-3409 | DOI: http://dx.doi.org/10.33448/rsd-v8i5.978

As coordenadas geográficas (Longitude e Latitude) foram obtidas através da utilização de GPS etrex 10 da marca Garmin e foram coletadas nos principais pontos do perímetro urbano do rio Grajaú, na cidade de Grajaú - MA.

Após o cabeçalho, seguiu-se com o preenchimento dos campos referentes aos indicadores de qualidade, com seus respectivos parâmetros de observação e análise, conforme são apresentados posteriormente.

\section{Resultados e indicadores de qualidade visual}

Os pontos de observação da paisagem adotados para a pesquisa foram enumerados no Quadro 2 e representados na imagem obtida no Google Earth, através dos pontos coletados pelo GPS Garmin etrex 10.

As localidades selecionadas para análise neste trabalho compreendem pontos tradicionalmente observados nos trabalhos de campo do Programa de Educação Tutorial PET/Ciências Naturais da Universidade Federal do Maranhão, Câmpus de Grajaú. As localidades observadas compreenderam desde os espaços de lazer às margens do rio até registros de impactos ambientais, como é o caso do despejo de efluentes.

$\mathrm{O}$ quadro abaixo apresenta alguns pontos registrados ao longo do trecho urbano em que percorre o rio na cidade de Grajaú. Cada ponto foi indicado com a nomenclatura reconhecida socialmente na cidade, além de terem sido registradas as coordenadas geográficas.

Quadro 2 - Posicionamento dos pontos de observação

\begin{tabular}{|c|c|c|}
\hline $\begin{array}{c}\text { Ponto de } \\
\text { observação }\end{array}$ & Coordenadas & Paisagens observadas \\
\hline 001 & $\begin{array}{c}05^{\circ} 49^{\prime} 30.1^{\prime \prime} \mathrm{S} \\
46^{\circ} 08^{\prime} 26,8^{\prime \prime} \mathrm{W}\end{array}$ & Prainha (a montante da ponte de cimento) \\
\hline 002 & $\begin{array}{c}05^{\circ} 49^{\prime} 18,2^{\prime \prime} \mathrm{S} \\
46^{\circ} 08^{\prime} 31,6 \text { ' W }\end{array}$ & Esgoto (próximo às Casas Oliveira) \\
\hline 003 & $\begin{array}{c}05^{\circ} 49^{\prime} 11,7^{\prime \prime} \mathrm{S} \\
46^{\circ} 08^{\prime} 38,4^{\prime \prime} \mathrm{W}\end{array}$ & Balneário Canecão \\
\hline 004 & $\begin{array}{c}05^{\circ} 49^{\prime} 01,3 " \mathrm{~S} \\
46^{\circ} 08^{\prime} 39,9^{\prime \prime} \mathrm{W}\end{array}$ & Porto da Nanana (ao lado da ponte de madeira) \\
\hline 005 & $\begin{array}{c}05^{\circ} 48^{\prime} 57,0^{\prime \prime} \mathrm{S} \\
46^{\circ} 08^{\prime} 40,1^{\prime \prime} \mathrm{W}\end{array}$ & Bar do Sirigueijo \\
\hline 006 & $\begin{array}{c}05^{\circ} 48^{\prime} 39,9^{\prime \prime} \mathrm{S} \\
46^{\circ} 08^{\prime} 20,3^{\prime \prime} \mathrm{W}\end{array}$ & Esgoto próximo ao Porto do Limoeiro \\
\hline
\end{tabular}

Fonte: Pesquisa de campo, 17 de julho de 2015. 


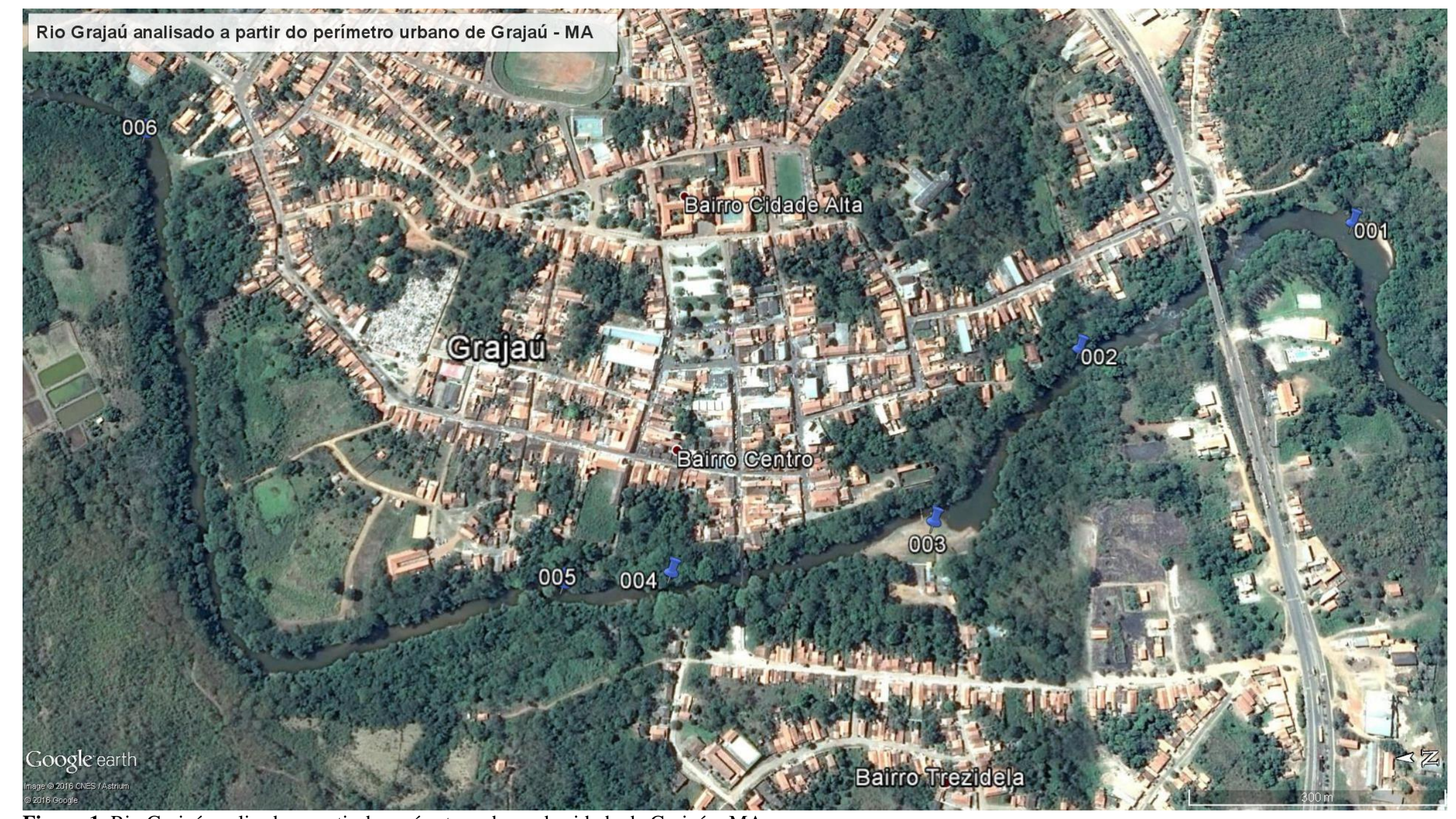

Figura 1. Rio Grajaú analisado a partir do perímetro urbano da cidade de Grajaú - MA

Fonte: Google Earth. 


\section{Res., Soc. Dev. 2019; 8(5):e2685978}

ISSN 2525-3409 | DOI: http://dx.doi.org/10.33448/rsd-v8i5.978

A análise da paisagem do perímetro urbano do Rio Grajaú a partir dos pontos de observação está representada no quadro geral da análise da qualidade visual da paisagem (Quadro 3) e os parâmetros gerais de avaliação da qualidade visual são descritos no Quadro 4.

Conforme já especificado na metodologia, Pires (2005) considerou quatro indicadores de qualidade visual para se analisar uma determinada paisagem, a saber: diversidade, naturalidade, singularidade e detratores.

Quadro 3 - Quadro geral da análise da qualidade visual da paisagem

\begin{tabular}{|c|c|c|c|c|c|c|}
\hline \multicolumn{7}{|c|}{ ANÁLISE DA QUALIDADE VISUAL DA PAISAGEM } \\
\hline $\begin{array}{c}\text { Ponto de } \\
\text { observação }\end{array}$ & \multicolumn{7}{c|}{ Indicadores considerados } \\
\hline $\mathbf{N}^{\circ}$ & Local & Diversidade & Naturalidade & Singularidade & Detratores & $\begin{array}{c}\text { Qualidade } \\
\text { visual }\end{array}$ \\
\hline $\mathbf{1}$ & 001 & $\mathrm{M}$ & $\mathrm{M}$ & $\mathrm{Lm}$ & $\mathrm{MI}$ & $\mathrm{M}$ \\
\hline $\mathbf{2}$ & 002 & $\mathrm{M}$ & $\mathrm{M}$ & $\mathrm{Lm}$ & $\mathrm{PI}$ & $\mathrm{M}$ \\
\hline $\mathbf{3}$ & 003 & $\mathrm{M}$ & $\mathrm{M}$ & $\mathrm{Lm}$ & $\mathrm{MI}$ & $\mathrm{M}$ \\
\hline $\mathbf{4}$ & 004 & $\mathrm{M}$ & $\mathrm{M}$ & $\mathrm{Lm}$ & $\mathrm{PI}$ & $\mathrm{M}$ \\
\hline $\mathbf{5}$ & 005 & $\mathrm{M}$ & $\mathrm{M}$ & $\mathrm{Lm}$ & $\mathrm{MI}$ & $\mathrm{M}$ \\
\hline $\mathbf{6}$ & 006 & $\mathrm{M}$ & $\mathrm{M}$ & $\mathrm{Lm}$ & $\mathrm{MI}$ & $\mathrm{M}$ \\
\hline
\end{tabular}

Legenda: M - Média; Lm - Limitada; MI - Média Intrusão; PI - Pequena Intrusão.

Fonte: Elaborado pelo autor.

Quadro 4 - Grade final de avaliação da qualidade visual da paisagem

\begin{tabular}{|c|l|}
\hline Classe de Qualidade Visual & \multicolumn{1}{c|}{ Parâmetros de Enquadramento } \\
\hline \multirow{3}{*}{ Qualidade visual superior (S) } & A) Níveis superiores de diversidade e de naturalidade; \\
& B) Com singularidade grande; \\
& C) Ausência de detratores, ou no Máximo, pequeno detrator. \\
\hline \multirow{3}{*}{ Qualidade visual média (M) } & A) Níveis médios de diversidade e de naturalidade; \\
& B) Com singularidade razoável; \\
& C) Presença de médios detratores. \\
\hline \multirow{3}{*}{ Qualidade visual inferior (I) } & A) Níveis inferiores de diversidade e de naturalidade; \\
& B) Ausência de singularidades ou limitadas; \\
& C) Presença de grandes detratores.
\end{tabular}

Fonte: Adaptado de Pires (2005).

No tocante ao indicador Diversidade, Pires (2005) argumenta que a variedade paisagística, isto é, a diversidade de elementos naturais ou artificiais é indicativa de que a paisagem possui maior valor que uma paisagem homogênea. $\mathrm{O}$ autor supracitado ao elaborar o indicador diversidade considera vários componentes visuais, tais como: relevo, vegetação, água e atividades humanas. Cada um destes componentes apresenta propriedades visuais próprias (forma/volume, linha, textura, cor/tonalidade), como se apresenta no quadro abaixo. 
Res., Soc. Dev. 2019; 8(5):e2685978

ISSN 2525-3409 | DOI: http://dx.doi.org/10.33448/rsd-v8i5.978

Quadro 5 - Diversidade visual

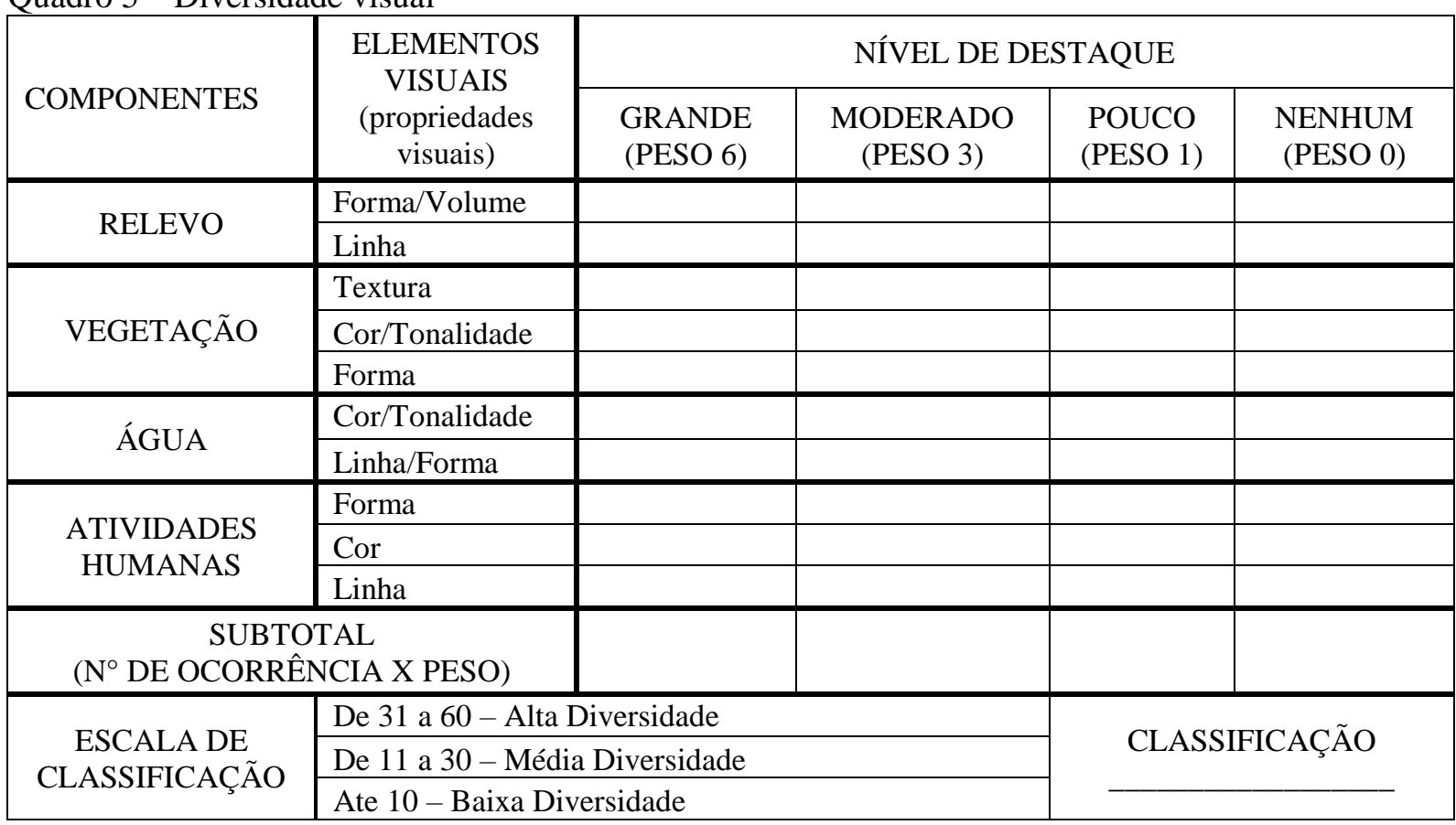

Fonte: Pires (2005).

Considerando tais componentes e suas propriedades no indicador Diversidade, os pontos observados exibem uma paisagem com relevo cuja forma apresenta declividade pouca acentuada e a linha de instabilidade do relevo, visualmente, pode ser classificada como moderada nos pontos 001, 002 e 006 e de pouco peso visual nos outros três pontos de observação: 003, 004 e 005.

A vegetação se apresenta moderada em textura, cor e forma nos pontos observáveis 001, 002, 004 e 005 e de pouco peso visual nos pontos 003 e 004, pois é possível observar a falta da mata ciliar (Figuras 2A e 2B). O elemento água apresenta coloração escura e linha/forma plana, sem muito movimento na superfície, em todos os pontos observados, sendo que em alguns lugares há o acúmulo de lodo. Vale frisar que a coloração mais escura da água se deve ao fato de a pesquisa ter sido realizada no período de estiagem e à presença de mata ciliar na maioria dos pontos observados, reduzindo a reflexão da luminosidade sobre a água. 

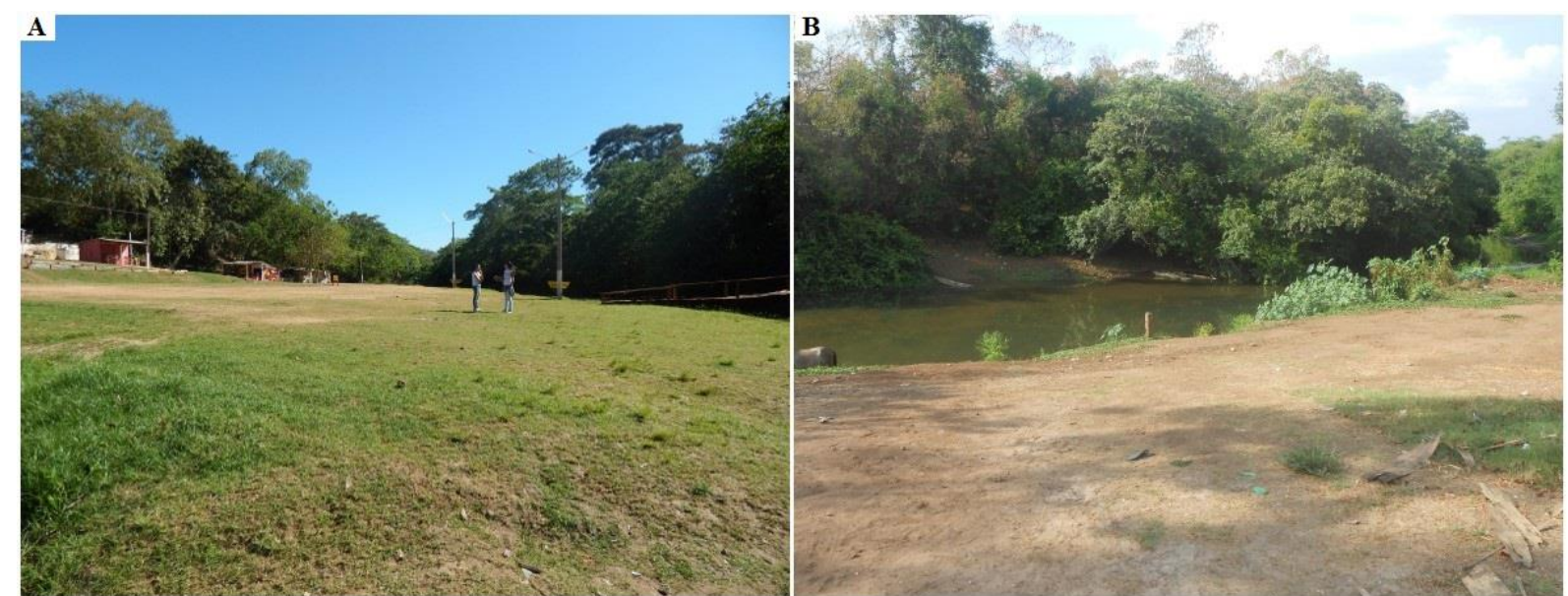

Figura 2. Áreas sem mata ciliar

Fonte: LIMA, C. A. de S. (2015).

As atividades humanas ou sua influência apresenta-se de forma moderada em forma, cor e linha, embora estas se apresentem em todos os pontos de observação, existem locais com maior interferência visível que outros.

No que se refere ao indicador Naturalidade, Pires (2005) considera-o como sendo a ausência ou insignificância, em uma determinada área, de elementos ou construções produzidas pela humanidade. A vegetação natural é a melhor forma de representar a naturalidade em nosso meio e ganha mais destaque se esta for remanescente de formações originais com pouca ou nenhuma interferência. $\mathrm{O}$ autor, ao elaborar o indicador Naturalidade, apresenta algumas classificações, cada qual com seus gradientes de modificação da paisagem natural, como se observa no quadro a seguir.

Quadro 6 - Naturalidade

\begin{tabular}{|l|c|}
\hline \multicolumn{1}{|c|}{$\begin{array}{c}\text { GRADIENTE DE MODIFICAÇÃO DA PAISAGEM } \\
\text { NATURAL }\end{array}$} & CLASSIFICAÇÃO \\
\hline $\begin{array}{l}\text { Paisagem natural sem alterações visíveis. } \\
\text { Paisagem natural pouco alterada. }\end{array}$ & NATURALIDADE SUPERIOR (S) \\
\hline $\begin{array}{l}\text { Paisagem tipicamente rural (campestre, cultivada, colonial). } \\
\text { Paisagem urbana ou Periurbana com entorno } \\
\text { predominantemente natural. }\end{array}$ & NATURALIDADE MÉDIA (M) \\
\hline $\begin{array}{l}\text { Paisagem urbana com poucos elementos naturais ou áreas } \\
\text { verdes. }\end{array}$ & NATURALIDADE INFERIOR (I) \\
\hline
\end{tabular}

Fonte: Adaptado de Pires (2005).

Considerando as classificações do indicador Naturalidade, junto de seus gradientes de modificação da paisagem, foi constatado que os pontos de observação analisados estão mais próximos da naturalidade média, pois não há entre os pontos estudados uma paisagem natural com poucas alterações, assim como não se observa uma paisagem considerada urbana 
com poucos elementos naturais. Existem, porém, pontos (001, 002, 004 e 005) com maior destaque para a vegetação do que outros, uma vez que há neles uma vegetação com predominância de árvores de médio porte e em outros há a ausência de vegetação, como se vê acima, nas figuras $2 \mathrm{~A}$ e $2 \mathrm{~B}$.

Outro indicador, segundo Pires (2005), é o da Singularidade, este se caracteriza por eventos naturais e manifestações de origem humana, como sítios arqueológicos, assim como de elementos visuais que apresentem unicidade, beleza, interesse histórico, raridade entre outras características que as tornam únicas. $\mathrm{O}$ autor utiliza alguns critérios de identificação, bem como critérios de classificação para caracterizar uma paisagem como singular, conforme os quadros abaixo:

Quadro 7 - Singularidade - critérios de identificação:

- Presença na paisagem de componentes e/ou suas propriedades visuais com atributos, tais como unicidade, raridade, grandiosidade, excepcional beleza;

- Grande amplitude visual (paisagem extremamente panorâmica);

- Ocorrência de fenômenos atmosféricos notáveis tais como nascer e pôr do sol, arco-íris, nuvens e nebulosidade, neve, geada;

- Presença de fauna;

- Paisagem natural sem alterações;

- Presença na paisagem de ocorrências ou aspectos ecológicos, geográficos ou ambientais de relevância educativa ou científica;

- Ocorrência de interesse histórico ou cultural que possua expressão visual.

Fonte: Adaptado de Pires (2005).

Quadro 8 - Singularidade - critérios de classificação:

\begin{tabular}{|l|c|}
\hline - Grande potencial de atratividade turística em nível nacional e internacional & $(\mathrm{Gr})$ \\
\hline - Razoável potencial de atratividade turística em nível estadual e subnacional & $(\mathrm{Rz})$ \\
\hline - Limitado potencial de atratividade turística em nível subestadual (regional) & $(\mathrm{Lm})$ \\
\hline
\end{tabular}

Fonte: Adaptado de Pires (2005).

$\mathrm{Na}$ análise do indicador Singularidade, os pontos de observação obtiveram singularidade limitada, já que os pontos estudados não possuem muitos elementos que os classifiquem como razoável ou grande potencial de atividades turísticas. Alguns dos pontos apresentam paisagens consideradas panorâmicas, mas restringem-se apenas a esse critério. Por exemplo, próximo ao ponto 004 há a Ponte Pênsil, construção de madeira que marca a paisagem e remonta a história da cidade, que possui 207 anos, sendo o principal elemento de ligação entre uma margem e outra do rio Grajaú - entre a Trizidela e o centro. Dela, é possível avistar a Catedral do Nosso Senhor do Bonfim, considerada uma das igrejas mais 
bonitas do Maranhão. A Ponte Pênsil e seu conjunto paisagístico, portanto, configura como uma "rugosidade"1 presente no perímetro estudado.

O último indicador que Pires (2005) coloca é o Detrator, sendo este o resultado das atividades humanas incididas sobre a natureza, o que faz com que a mesma se afaste de suas características naturais, diminuindo a qualidade visual da paisagem. Todavia, o autor coloca que processos naturais (erosão, sedimentação, maremotos, atividades vulcânicas, entre outros) também podem causar detração na qualidade visual da paisagem, sendo que tais eventos podem ser influenciados por atividades humanas. Assim como Pires (2005), este trabalho considerou apenas as detrações causadas pelas atividades humanas. De acordo com a presença de elementos classificados como detratores, têm-se os critérios de classificação, que podem ser observados no Quadro 9.

Quadro 9- Detratores - critérios de classificação

\begin{tabular}{|l|c|}
\hline - Pequena intrusão & (PI) \\
\hline - Média intrusão & (MI) \\
\hline - Grande intrusão & (GI) \\
\hline
\end{tabular}

Fonte: Adaptado de Pires (2005).

Diante dos elementos considerados como intrusões dentro do indicador Detrator, os pontos observados apresentaram pequenas e médias intrusões. Aqueles considerados com pequenas intrusões são os pontos 002 e 004, e os com médias intrusões são os pontos 001, 003, 005 e 006.

Os pontos considerados com pequenas intrusões ainda apresentam uma mata ciliar mais conservada do que os outros pontos, embora haja neles despejos de efluentes (esgoto proveniente do centro da cidade e bairros adjacentes).

Os pontos considerados com médios processos detratores, além de apresentarem indícios de despejo de efluentes, possuem atividades comerciais (bares) no local (Figura 3A). Em dois deles existem depósitos de sedimentos, ocasionando o assoreamento do leito do rio, bem como se observa, em algumas áreas destes pontos, a falta da mata ciliar, já citada. No ponto 005 (Figura 3B), conhecido como Bar do Sirigueijo, existe dentro do rio escorregador,

\footnotetext{
1 "Chamemos de rugosidade ao que fica do passado como forma, espaço construído, paisagem, o que resta do processo de supressão, acumulação, superposição, com que as coisas se substituem e acumulam em todos os lugares. As rugosidades se apresentam como formas isoladas ou como arranjos" (Santos, 2012, p. 140).
} 


\section{Res., Soc. Dev. 2019; 8(5):e2685978}

ISSN 2525-3409 | DOI: http://dx.doi.org/10.33448/rsd-v8i5.978

balanços e pneus para recreação, embora, a poucos metros a jusante do local, haja o lançamento de efluentes.

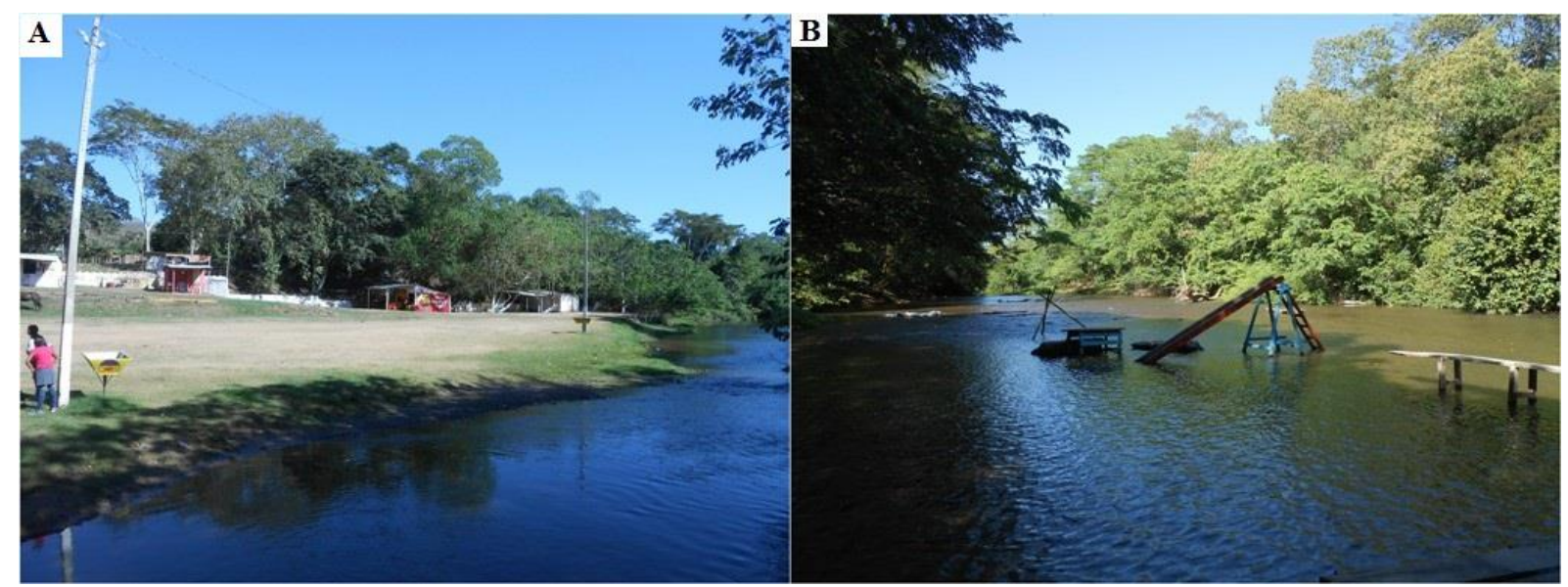

Figura 3. Dois pontos com média intrusão Fonte: LIMA, C. A. de S. (2015).

Diante do exposto, os pontos observados foram considerados de média qualidade visual, pois nenhum dos indicadores se apresentou em graus superiores de classificação e, embora haja pontos de observação com alguns indicadores em graus inferiores, optou-se por considerar a maior ocorrência de indicadores, que foi média.

\section{Percepção Ambiental: considerações a partir do modo de perceber o rio Grajaú}

A outra etapa de desenvolvimento metodológico deste trabalho foi buscar conhecer a percepção dos moradores da cidade de Grajaú com relação às formas de uso e aos problemas ambientais que impactam o rio Grajaú no trecho urbano. Para isso foram realizadas entrevistas com alguns moradores. Nessa etapa optou-se por fazer as entrevistas de forma aleatória e apenas uma amostra da população grajauense, ao todo foram entrevistadas 17 pessoas, entre homens e mulheres. Esta entrevista foi construída de forma semiestruturada.

O roteiro das entrevistas iniciou-se com a coleta de alguns dados dos entrevistados, tais como: nome, escolaridade, idade, entre outros. Entre os entrevistados constam 11 homens e seis mulheres, sendo ambos de várias idades e diferentes escolaridades.

A segunda questão referia-se à quantidade de anos que os entrevistados moram ou frequentam a cidade de Grajaú. Quase todos moram na cidade, apenas duas pessoas disseram que vêm à cidade apenas em períodos de férias. 
A terceira questão tinha como objetivo saber se o rio tinha alguma influência na vida deles e qual era sua importância. Dos 17 entrevistados, todos responderam positivamente. Destes, a maioria respondeu que o rio era ou é muito importante em função do lazer, para lavar roupas, pescar, coleta e consumo de água (antigamente).

Em outra questão buscou-se saber os pontos do rio utilizados pelos entrevistados. A maioria dos entrevistados respondeu que frequentam os balneários, sendo os mais utilizados os balneários Canecão, Sirigueijo e Prainha.

A questão seguinte tinha como ponto principal identificar o local mais agradável para visitação na opinião dos entrevistados. Os resultados estão apresentados no Gráfico 1:

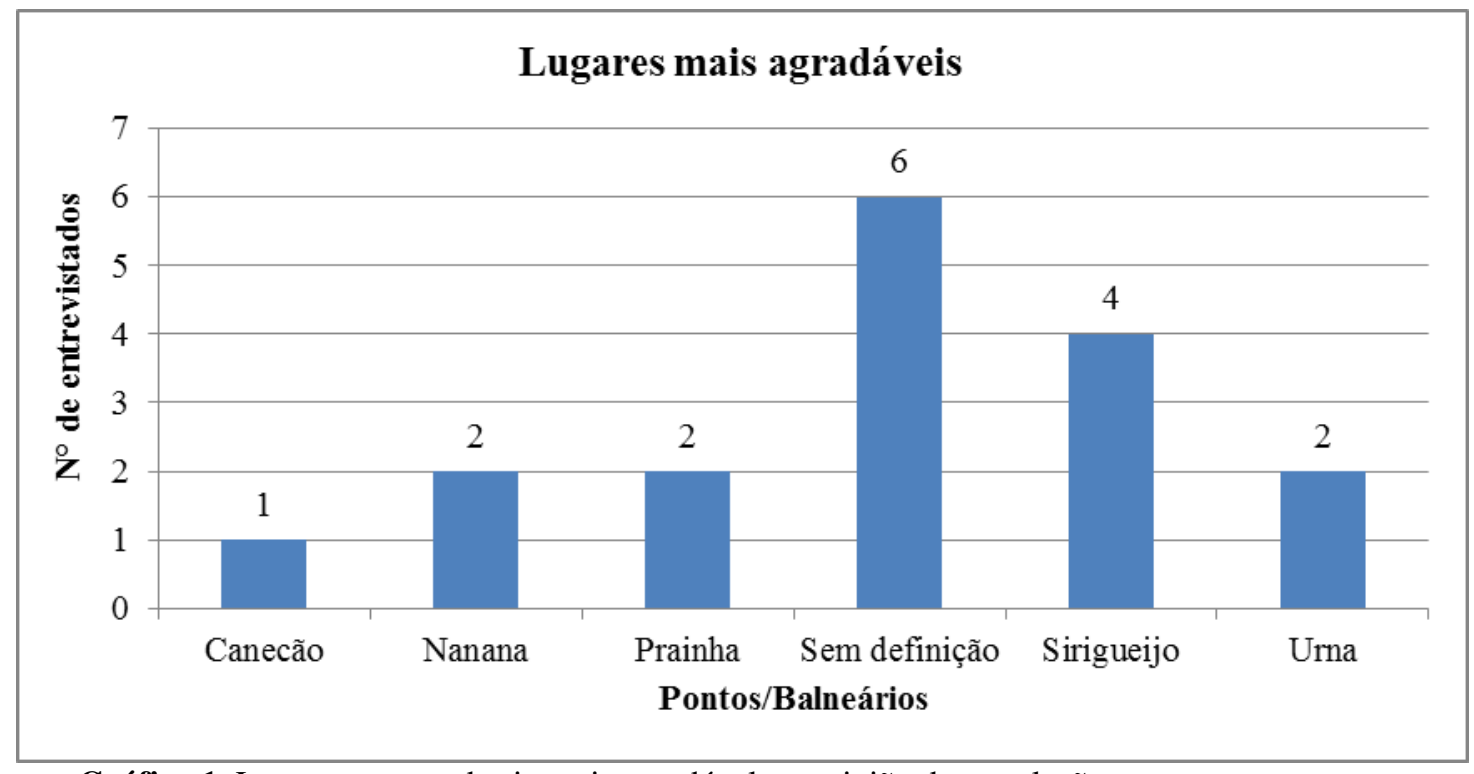

Gráfico 1. Lugar ou ponto do rio mais agradável na opinião da população Fonte: Pesquisa de campo, 2015.

Como pode ser observado no gráfico, dos 17 entrevistados, seis responderam que não têm um lugar definido como o mais preferível para visitação no trecho do perímetro urbano do Rio Grajaú, sendo que um desses disse que gosta de todos os lugares, pois aonde chega está satisfeito. Os entrevistados que disseram achar a Prainha mais agradável justificaram dizendo que a mesma é o ponto menos poluído dentro da cidade de Grajaú. O ponto denominado Urna era localizado abaixo do Sirigueijo e hoje não existe mais como ponto de lazer.

O sexto questionamento pretendia saber se os moradores haviam percebido alguma mudança na característica do rio Grajaú e seu entorno no período que mora ou frequenta o local. Todos disseram que houve mudanças nas características do rio, e as mais citadas pelos entrevistados foram a diminuição da vazão e a redução da mata ciliar em alguns pontos. 
ISSN 2525-3409 | DOI: http://dx.doi.org/10.33448/rsd-v8i5.978

A sétima questão era a seguinte: "Em sua opinião, quais os responsáveis pelas mudanças ocorridas no rio?" As respostas foram as seguintes:

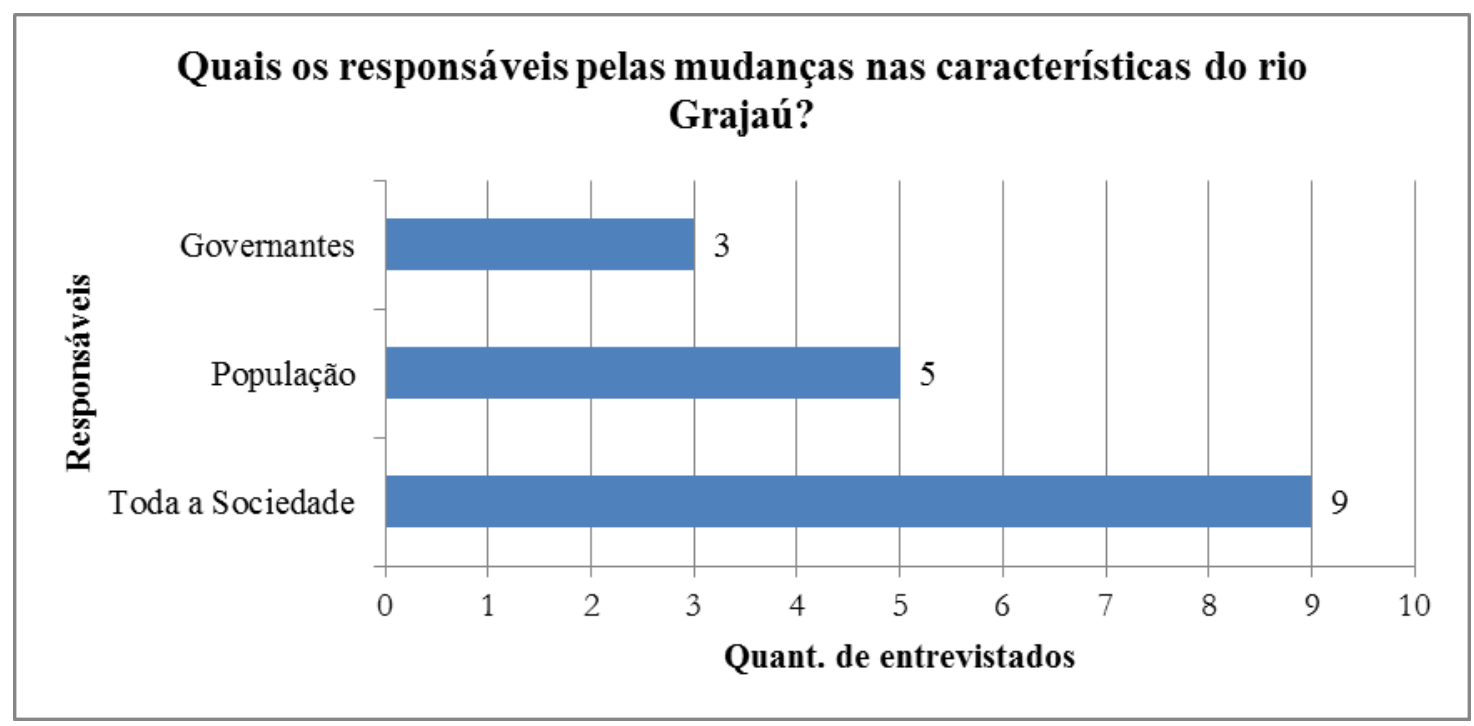

Gráfico 2. Quais os responsáveis pelas mudanças ocorridas na paisagem do Rio Grajaú? Fonte: Pesquisa de campo, 2015.

Como se observa no gráfico, a maioria dos entrevistados acredita que a culpa das mudanças ocorridas nas características do rio é da sociedade em geral (englobando a população, os governantes e as empresas). Nesta questão, os próprios entrevistados se incluem como culpados.

O oitavo ponto do questionário tinha com finalidade identificar os impactos ambientais, observados pelos entrevistados, sobre o rio e seu entorno, no trecho urbano de Grajaú. O item mais destacado pelos entrevistados foi a poluição do rio por esgoto e lixo, jogados em suas margens pelos próprios moradores da cidade. Outros possíveis impactos ambientais destacados pelos entrevistados foram as queimadas e o desmatamento de trechos do rio para a construção de espaços de lazer, entre outras atividades.

A nona questão abordou se os entrevistados tinham lembranças ou relatos através dos quais fosse possível comparar a paisagem do rio Grajaú antes e atualmente. Os fatos mais citados na comparação dos moradores foram a diminuição da vazão do rio e o aspecto visual da água, o qual eles consideraram mais límpida outrora.

A décima questão tinha por finalidade procurar saber a opinião/percepção dos entrevistados sobre alguns temas ligados ao rio Grajaú. Tais temas estão expostos no gráfico a seguir: 


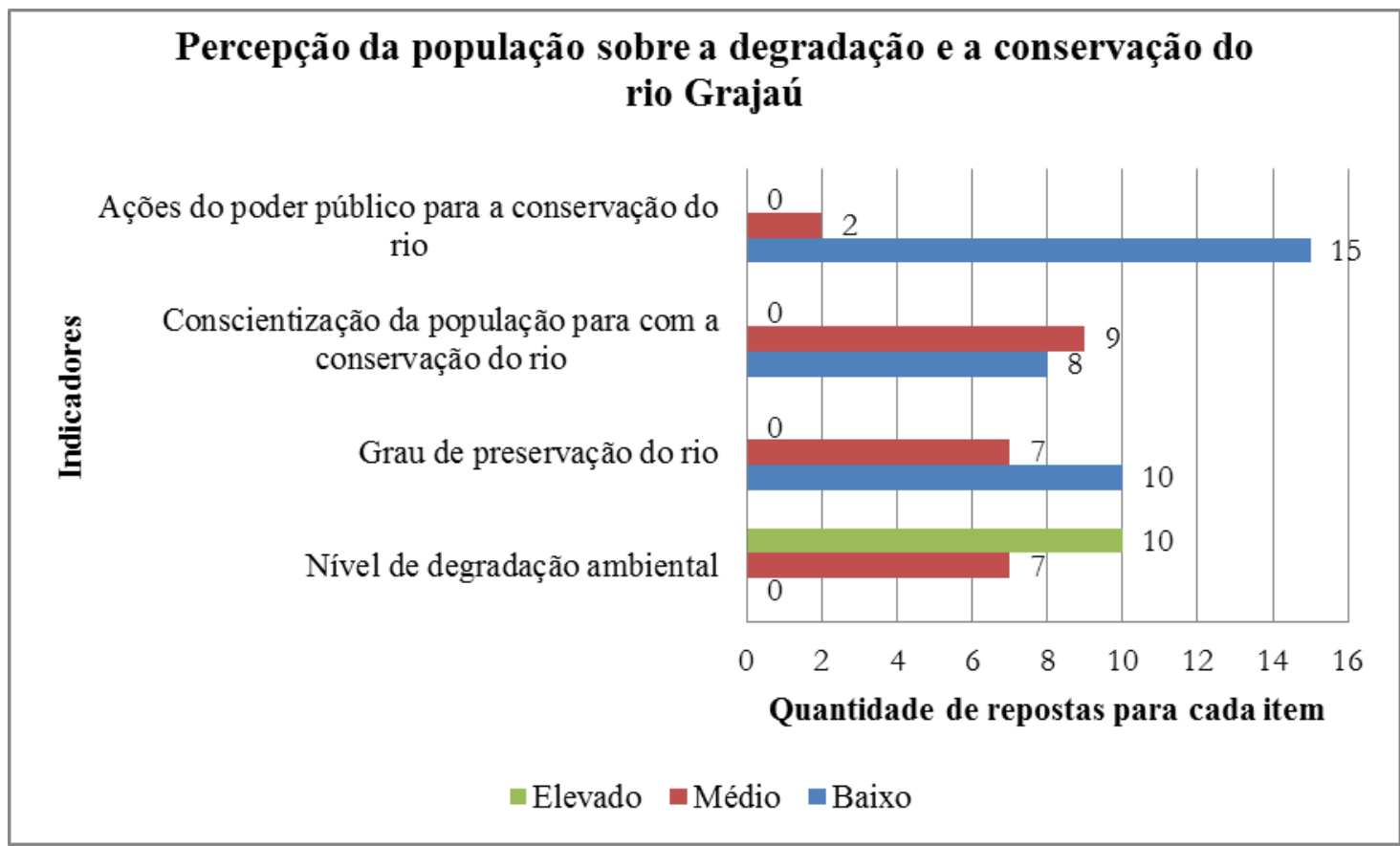

Gráfico 3. Percepção da população sobre a degradação e a conservação do Rio Grajaú Fonte: Pesquisa de campo, 2015.

A maioria dos entrevistados acredita que o poder público não realiza ações de incentivo à conservação do rio Grajaú. Ainda que o gráfico mostre que a população tem baixo e médio grau de "conscientização", pode-se inferir a partir das entrevistas realizadas que há certa sensibilização para com a conservação do rio Grajaú, mas, ainda, não é possível afirmar sobre a formação de uma conscientização para a conservação ambiental. Sobre a preservação do rio Grajaú, a maioria dos entrevistados acredita que o rio tem baixo índice de preservação, consequentemente apresenta alto índice de degradação ambiental.

Cabe aqui destacar que existem, na cidade de Grajaú, pequenas ações ou pontapés iniciais para se debaterem os problemas ambientais sobre o rio Grajaú. O Programa de Educação Tutorial - PET/Ciências Naturais, da Universidade Federal do Maranhão/Câmpus de Grajaú, já realizou, em parceria com a Secretaria de Meio Ambiente, ações para a conscientização no Balneário Canecão, bem como em outros balneários da cidade. O referido programa também realiza seminários nas escolas, abordando geralmente temas de caráter ambiental e o rio Grajaú é o principal tema e cenário. Outra ação que merece destaque é a do senhor conhecido como Rubens Natureza, o qual afixa cartazes por toda a cidade, principalmente em árvores às margens do rio e nas praças da cidade. Tais cartazes possuem frases que evocam a educação ambiental e a preservação.

No último mês do ano de 2015, o Programa Institucional de Bolsas de Iniciação a Docência (PIBID), da Universidade Federal do Maranhão - Câmpus de Grajaú, realizou, 
Res., Soc. Dev. 2019; 8(5):e2685978

ISSN 2525-3409 | DOI: http://dx.doi.org/10.33448/rsd-v8i5.978

junto com calouros das turmas de Ciências Humanas e Ciências Naturais e da ONG Guardiões do Rio Grajaú, uma coleta de lixo por todo o percurso do rio, no perímetro urbano de Grajaú.

\section{Considerações finais}

Diante dos resultados, concluiu-se que a paisagem do rio, no perímetro urbano de Grajaú, perdeu em qualidade ambiental, pois se percebe que a urbanização em torno do rio produz efluentes, que são despejados diretamente no rio, sem nenhum tratamento. No rio é possível perceber a retirada de vegetação com o intuito de se construir pontos de lazer, bem como áreas nas quais já existem processos de assoreamento.

A população grajauense, embora tenha sensibilidade em relação à condição em que se encontra o rio Grajaú, não possui satisfatoriamente uma conscientização voltada para ações de caráter ambiental. Os moradores ficam tristes quando comparam o rio antigamente com a situação atual. O rio possuía uma vegetação mais densa que a de hoje e a vazão de água era maior durante todo o ano. Hoje é possível perceber, no perímetro urbano de Grajaú, o lançamento de efluentes dentro do rio, sendo que parte da água consumida pela população de alguns bairros provém desse curso d'água.

Os indicadores de qualidade visual das paisagens, embora atestem para uma média diversidade e média naturalidade, confirmam que as paisagens possuem interferência do homem em seu meio, possibilitando assim entender que o rio Grajaú perdeu em sua qualidade visual. Na análise do indicador detrator foi possível perceber alguns impactos, tais como: assoreamento, lançamento de efluentes diretamente no rio, sem qualquer tratamento, lixo nas margens e dentro do rio e solo desnudo.

A paisagem existente ao redor do rio já foi modificada e, através dos resultados das entrevistas com os moradores, puderam-se observar poucas ações de caráter educativo e ambiental, para uma melhor educação das pessoas que usufruíam/usufruem dos recursos naturais presentes no rio Grajaú.

Vale frisar novamente que é preciso haver ações voltadas para a educação ambiental ou minimamente para discutir os problemas presentes no rio e seu entorno, na cidade de Grajaú. É preciso que as autoridades competentes façam políticas públicas voltadas para a educação ambiental ou coloquem em exercício as que já existem.

Concluiu-se ainda que a paisagem do rio Grajaú está se tornando cada vez mais humanizada, longe de sua naturalidade. $\mathrm{O}$ rio está sumindo em meio às atividades e impactos 
causados pelo homem e, embora se tenha sensibilidade para com a situação atual do rio, são poucas as atividades de incentivo a sua conservação.

Deve-se frisar também que os estudos de percepção e indicadores de qualidade visual limitam-se a aspectos da subjetividade humana, tanto dos investigadores quanto dos sujeitos entrevistados, o que expõe observações limitadas, sentimentos e emoções. Consultar os sujeitos é uma forma de mostrar a evolução da paisagem temporalmente, no entanto, sugerese que outros estudos possam ser elaborados com a intencionalidade de mensurar impactos ambientais na paisagem urbana do rio Grajaú, utilizando-se de análises físico-químicas dos recursos hídricos, monitoramento do desmatamento da vegetação ciliar e o consequente assoreamento do leito do rio principal.

\section{Referências}

Amorim Filho, O. B. (2002). Os estudos da percepção como a última fronteira da gestão ambiental. Anais do II Simpósio Situação Ambiental e Qualidade de Vida na Região Metropolitana de Belo Horizonte e Minas Gerais. Associação Brasileira de Geologia de Engenharia. Belo Horizonte, p. 16-20.

Bertrand, G. (2004). Paisagem e geografia física global: esboço metodológico. $R a^{\prime} e \mathrm{Ga}-\mathrm{O}$ Espaço Geográfico em Análise, 8(1), 141-152.

Cavalcanti, A. P. B. (2011). Percepção e paisagem geográfica: procedimentos teóricos e metodológicos da pesquisa de campo. Geografia e Pesquisa, 5(1), 103-122.

Maciel, C. A. A. (2001). Morfologia da paisagem e imaginário geográfico: uma encruzilhada onto-gnoseológica. GEOgraphia, 3(6), 71-82. Disponível em: <https://doi.org/10.22409/GEOgraphia2001.v3i6.a13412>. Acesso em: 26 dez. 2017.

Marin, A. A. (2008). Pesquisa em educação ambiental e percepção ambiental. Pesquisa em Educação Ambiental, 3(1), 203-222.

Moura, D. V. \& Simões, C. S. (2010). A evolução histórica do conceito de paisagem. Ambiente \& Educação, 15(1), 179-186.

Oliveira, L. de. (2012). Percepção Ambiental. Geografia e Pesquisa, 6(2), 56-72.

Pires, P. dos S. (2005). A análise de indicadores da qualidade visual como etapa da caracterização de paisagens turísticas: uma aplicação no distrito-sede de Porto Belo - SC. Turismo: Visão e Ação, 7(3), 417-426.

Salgueiro, T. B. (2001). Paisagem e Geografia. Finisterra, Lisboa, 36(72), $37-53$. 


\section{Res., Soc. Dev. 2019; 8(5):e2685978}

ISSN 2525-3409 | DOI: http://dx.doi.org/10.33448/rsd-v8i5.978

Salvio, V. L. (2008). Paisagens dos sítios arqueológicos de pintura rupestre da região de Diamantina-MG. Dissertação de Mestrado em Geografia. Universidade Federal de Minas Gerais, Belo Horizonte.

Santiago-Almeida, M. M. (2011). Minidicionário livre da língua portuguesa. São Paulo: Hedra.

Santos, M. (2012). A Natureza do Espaço: Técnica e Tempo. Razão e Emoção. São Paulo: Editora da Universidade de São Paulo.

Sauer, C. O. (1998). A morfologia da paisagem. En: Corrêa; R. L. \& Rozendahl, Z. (Org.). Paisagem, tempo e cultura. Rio de Janeiro: EdUERJ, p. 12-74.

Schier, R. A. (2003). Trajetórias do conceito de paisagem na geografia. Ra'e Ga-O Espaço Geográfico em Análise, 7(1), 79-85.

Tuan, Yi-fu. (2012). Topofilia: um estudo da percepção, atitudes e valores do meio ambiente. Londrina: EDUEL.

\section{Porcentagem de contribuição de cada autor no manuscrito \\ Carlos Antonio de Souza Lima - 50\% \\ Marcos Nicolau Santos da Silva - 50\%}

